This is an Author's Accepted Manuscript of an article published in

D. Amitrano, G. Di Martino, A. Iodice, D. Riccio, G. Ruello, F. Ciervo, M. N. Papa, and Y. Koussoubè, "Effectiveness of high resolution SAR for water resource management in low-income semi-arid countries," Int. J. Remote Sens., vol. 35, no. 1, pp. 70-88, 2014. (C) Taylor \& Francis, available online at:

http://www.tandfonline.com/10.1080/01431161.2013.862605. 


\title{
Effectiveness of high-resolution SAR for water resource management in low-income semi-arid countries
}

\author{
Donato Amitrano ${ }^{a}$, Gerardo Di Martino ${ }^{a}$, Antonio Iodice ${ }^{a}$, Daniele Riccio ${ }^{a}$, Giuseppe \\ Ruello $^{a}$, Maria Nicolina Papa $^{b}$, Fabio Ciervo $^{c}$ and Youssouf Koussoube ${ }^{c}$ \\ ${ }^{a}$ Department of Electrical Engineering and Information Technology, University of Napoli \\ Federico II, via Claudio 21, 80125 Napoli, Italy; ${ }^{b}$ Department of Civil Engineering, \\ University of Salerno, Salerno, Italy; ${ }^{c}$ Laboratoire dhydrogologie - Unit de formation et \\ de recherche en Sciences de la vie et de la terre, University of Ouagadougou, \\ Ouagadougou, Burkina Faso \\ (Pre-print version, December 12, 2013 \\ This work has been published on \\ International Journal of Remote Sensing, vol. 35, no. 1, pp. 70-88, 2014)
}

\begin{abstract}
This paper presents an efficient framework and a sustainable pilot project on the effective use of spaceborne Synthetic Aperture Radar (SAR) in low income countries and semi-arid climatic contexts. The technical efficiency was pursued by integrating SAR models and hydrological assessment methods; the socioeconomical sustainability was guaranteed by the joint work of scientists, technicians and volunteers. The pilot project was developed in the Yatenga region, a Sahelian area in northern Burkina Faso. In particular, an original development of SAR Interferometry algorithms was tailored to the peculiar climate, the soil characteristics, and the land-cover of the semi-arid regions. A digital elevation model (DEM) was derived and an original approach based on the use of SAR amplitude images is proposed for its validation. The achieved DEM resolution $(9 \mathrm{~m})$ is significantly better than that of the previously available DEMs in the study area $(30 \mathrm{~m})$. Based on the DEM, the soil sedimentation rate of small reservoirs has been estimated together with the average soil-loss in the contributing catchments due to the erosion process. A multi-temporal filter was implemented on the SAR images for monitoring of water intake volume in small reservoirs, and its seasonal evolution. The developed tools provide an innovative contribution for the improvement of water resource management in the study area. This approach is repeatable and scalable to suit situations with similar economic and climatic conditions.
\end{abstract}

\section{Introduction}

More than 2.5 billion people in the world live with less than 2.5 dollars per day and depend on subsistence agriculture (UNDP 2011) Their existence is made even more fragile and unsafe by major environmental events, occurring more and more frequently due to climate changes. Hence, management of the physical environment is hydrological modeling can provide a crucial support but it requires a huge amount of information distributed geographically and periodically (Bates et al. 2008), (Perry et al. 2009). This information could be obtained by deploying a distributed hydrological monitoring network. In low income countries this costly deployment is inapplicable, due to economic, social and technological reasons.

Remote sensing instruments can be a powerful support for hydrological model developers. They give the ability to estimate several governing variables of the hy- 
drological cycle for wide regions, with spatial resolution and revisit time compatible with many hydrological applications. Valuable projects exist already in literature (ESA 2012), (Fernandez et al. 2009). launched by the European Space Agency in 2002 supported African institutions to access Earth observation data for water related projects. Significant results have been obtained also by the GLOWA Volta project, that provided an analysis of the physical and socio-economic determinants of the hydrological cycle within the Volta Basin (van de Giesen et al. 2003).

Nevertheless, in low income countries, where a synoptic view would be extremely useful for resource identification and management, satellite data are scarcely used. Despite the fact that orbital laws oblige satellites to cover almost the whole Earth, in many low income regions, satellite data are rare, or not acquired at all. Data acquisition is not requested mainly because of the (logical) prejudice that remote sensing could never support the political and scientific communities of low income countries without extra (costly) side activities.

One of the goals of this paper is the overturning of this paradigm, demonstrating that the joint work of scientists, technicians and volunteers can provide useful, nocost products for these countries. Space agencies can promote the data and explore a new business sector. Researchers and technicians can gain both technical and cultural benefits, along with the young students involved in the project. Beneficiaries can be advantaged in the short-term in the exploitation of the products and in the long-term through the creation of a research system, that is expected to produce socio-economic results.

Remote sensing approaches, methods and technologies need to be customized to each specific context. In particular, in this paper, we focus on semi-arid regions, defined as areas where the annual potential evapo-transpiration rate is higher than the precipitation one (Peel, Finlayson, and McMahon 2007). These areas are characterized by variable hydrological regimes, with the alternation of intense rainy and long dry seasons. In this context, farmers and decision makers face extreme constraints often exacerbated by both seasonal droughts and floods that threaten the regional food security. Groundwater is limited, and must be shared between agriculture, farming and human consumption.

In this paper we present the pilot project "WAter Resource Management in SemiArid Regions"(WARM-SAR), that was developed in Burkina Faso, providing a support to decision makers in the field of hydrology and land management, based on the use of high resolution Synthetic Aperture Radar (SAR) sensors. The philosophy and methodology of the project are presented in Section 2.

During the project, we used a set of SAR images, provided at no cost by the Italian Space Agency in the frame of the AO2007 call (Di Martino et al. 2012a,b). The images are relevant to the Yatenga region, a Sahelian area of the North of Burkina Faso. The area, whose complete description is presented in Section 3, is characterized by a two-season climate, with the alternation of extreme weather conditions. Floods occur in the June September rainy season, and droughts are frequent at the end of the October May dry season (Sienou and Karduck 2012).

In Burkina Faso, the farmers mainly accumulate the wet season rain in smallcapacity reservoirs. The location of the dams and the use of water are often left to the farmers experience and they are neither planned nor optimized. The exact number, location and capacity of small reservoirs are not recorded. Such a situation is at the same time a scientific and technical challenge and, from the remote sensing viewpoint, an opportunity for developing ad hoc algorithms.

The analysis of this context led to a definition of the appropriate technical actions necessary in order to exploit the available data. The implemented standard and 
innovative remote sensing techniques exploit the specific climate for extracting the required physical parameters. In particular, in Section 4, we present the Interferometric SAR (InSAR) algorithm adopted to extract the DEM. This was then used to measure the reservoir capacity and its reduction with time due to the deposition of water-transported sediments. In Section 5, we present how the COSMO-SkyMed data allowed the estimation of water intake in the small reservoirs.

\section{Project rationale}

The adoption of a new technology can be effective only with the participation of all the stakeholders. The pilot project (Di Martino et al. 2012a) presented in this paper involved local communities, University researchers from Italy (Napoli and Salerno) and Burkina Faso (Ouagadougou), volunteers of the non-profit humanitarian association Engineering Without Borders. All the participants contributed with their cultural skills, and received satisfactory results and advantages.

The first step of such a holistic approach is the analysis of the working environment. An accurate analysis of the case study (see Section 3), from both physical and social perspectives, allows the definition of the user needs and the development of techniques appropriate to the context.

Once the case study is analyzed, the next step is to outline the activities needed to provide the necessary solutions to the beneficiaries. In water management problems, a huge amount of data with high spatial and temporal resolution is often needed and usually not available in low income countries. In this paper, part of the data are provided by the remote sensing instruments. For instance, most of the hydrological modeling requires an accurate DEM, that is not easy to obtain in low income countries. In Section 4 we present the InSAR technique used for the DEM generation and the end product.

Value added products have been then obtained by integrating complementary remote sensing and hydrology skills. The hydrological models are fed by remote sensing data, whose interpretation benefits from the interaction with hydrologists (Di Martino et al. 2011). Such an approach is detailed in Sections 4 and 5, where the proposed algorithms are tailored to the specifics of the semi-arid climate.

The derivation of DEMs from remotely sensed data has partly filled the gap. DEMs are now freely available with a global coverage, e.g. SRTM (90 m resolution) and ASTER (30 m resolution)

\section{Case study}

This paper presents the first implementation of the philosophy and methodology described above. A set of 16 stripmap and 7 spotlight images with coverage of almost one year and a half, including two rainy seasons, was acquired for the project. The SAR images cover a rectangular area of almost $1600 \mathrm{~km}^{2}$ of the Yatenga district (see Figure 1) in the north of Burkina Faso, a small country $\left(240000 \mathrm{~km}^{2}\right)$ located in West Africa.

From the social viewpoint, nearly $80 \%$ of the 14 million inhabitants (INSD 2006), live in rural areas and the main activity consists of subsistence farming and ranching. The country is under-developed. According to the human development index it is classified amongst the bottom seven countries of a total of 187 countries in the world (UNDP 2011). More than two million people are in food insecurity and about $34 \%$ of the population is subject to chronic malnutrition (FAO 2012) . Exportation 


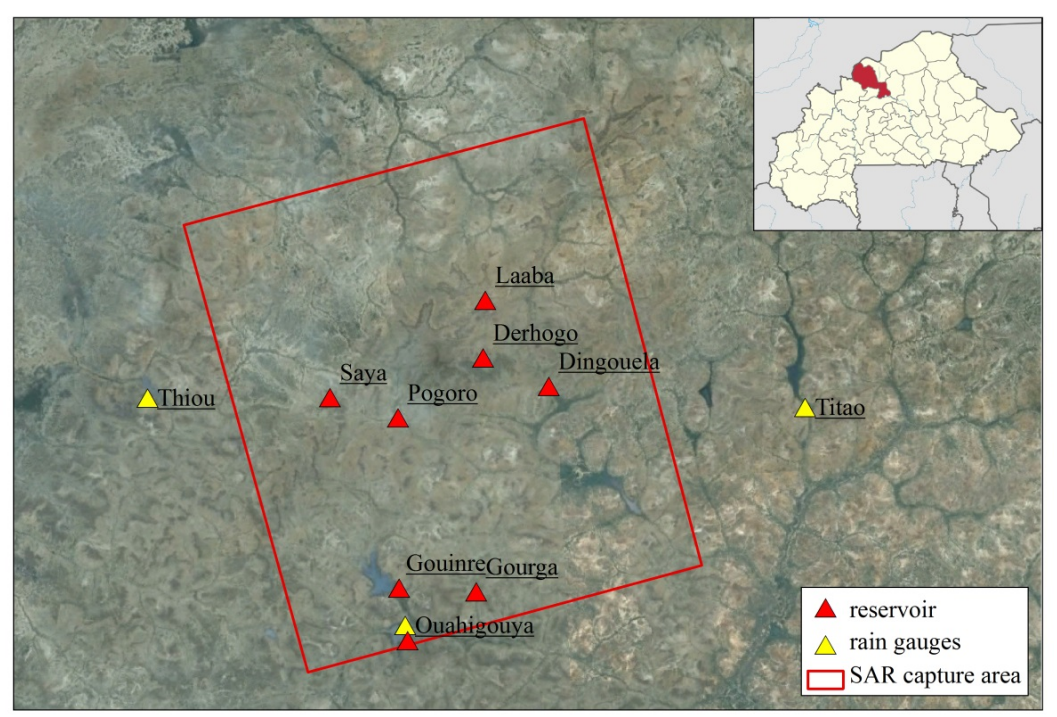

Figure 1.: Google Earth view of the Yatenga district, Burkina Faso.

items mainly consist of cotton, cattle and gold. In recent decades the country has witnessed the development of both illegal and authorized mining activities. From the geological viewpoint, the basement of the Burkina Faso is marked by two main, geographically well-distributed, features relevant to different ages:

- The Paleoproterozoic crystalline basement, covering $82 \%$ of the country, is composed of volcano-sedimentary and volcanic rocks and granitoids (Castaing et al. 2013);

- The Neoproterozoic sedimentary basin, covering northern (including the Yatenga region), western and eastern borders, rests on crystalline formations. Among sedimentary rocks, there is a variety of sandstone and limestone (Koussoube 2010)

From the climate viewpoint, annually Burkina Faso experiences a wet season, from May to October, characterized by short intense storms, and a dry season, from November to April. Total seasonal rainfall ranges from 100 to $650 \mathrm{~mm}$ in the north, and from $650 \mathrm{~mm}$ to over $1100 \mathrm{~mm}$ in the south of the country. The nonuniform spatial distribution and the seasonal inter-annual variations have a strong impact on vegetation. Therefore, there is a Sahelian zone in the north, and a Sudan-Sahelian zone in the center and in the south of the country (Peel, Finlayson, and McMahon 2007). The area covered by SAR images (see the red rectangle in Figure 1) is located in the Sahelian zone; the three rainfall gauge stations close to the study area (see Figure 1) are: Ouahigouya $\left(13^{\circ} 35 \mathrm{~N}, 2^{\circ} 26 \mathrm{~W}\right.$, elevation: $329 \mathrm{~m}$ a.s.l), Thiou $\left(13^{\circ} 49 \mathrm{~N}, 2^{\circ} 40 \mathrm{~W}\right.$, elevation: $303 \mathrm{~m}$ a.s.l) and Titao $\left(13^{\circ} 46 \mathrm{~N}, 2^{\circ} 04 \mathrm{~W}\right.$, elevation: $329 \mathrm{~m}$ a.s.l). In Figure 2 the annual rainfalls measured in the last 40 years are reported. The historical records are not available for the period of 20042010 for all the stations, and missing for a few other years. Despite the area being almost flat, the annual rainfall differs significantly between neighboring villages; the average over the last 40 years is $483 \mathrm{~mm}$ at Titao, $527 \mathrm{~mm}$ at Thiou and $610 \mathrm{~mm}$ at Ouahigouya. Rainfall in the region is characterized by large variations through the years. For example, annual rainfall in Thiou ranged from 309 to 775 $\mathrm{mm}$ over the past 40 years. This variation had a great impact on crop production. For example millet, that is one of the most widespread products in the area, has 
a vegetative life of 90 days and cannot develop without irrigation if the annual rainfall is lower than $350 \mathrm{~mm}$.

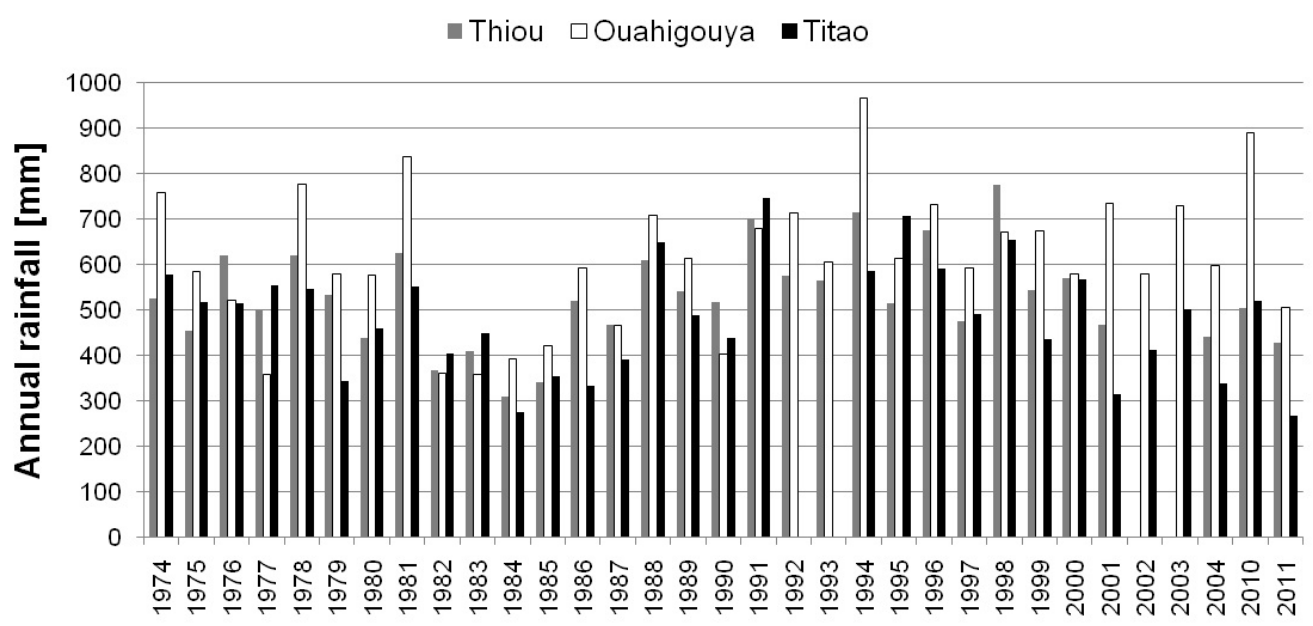

Figure 2.: Cumulated annual rainfall in millimeters measured at Ouahigouya $\left(13^{\circ} 35 \mathrm{~N}, 2^{\circ} 26 \mathrm{~W}\right.$, elevation: $329 \mathrm{~m}$ a.s.l $)$, Thiou $\left(13^{\circ} 49 \mathrm{~N}, 2^{\circ} 40 \mathrm{~W}\right.$, elevation: 303 $\mathrm{m}$ a.s.l) and Titao $\left(13^{\circ} 46 \mathrm{~N}, 2^{\circ} 04 \mathrm{~W}\right.$, elevation: $329 \mathrm{~m}$ a.s.l $)$.

In the past forty years West Africa experienced a long dry period. At Ouahigouya, the average annual rainfall in the period from 1922-1969 was $716 \mathrm{~mm}$ (Albergel and Lamachre 1993), while the average of the period from 1974-2011 was $610 \mathrm{~mm}$ (see Figure 2).

In Figure 3 the average monthly rainfall for the three stations is reported. About $75 \%$ of the rain falls during the months of July, August, and September, while from November to April rainfall is lower than $20 \mathrm{~mm}$ per month.

From the agricultural viewpoint, Burkina Faso presents arid soils. In the Yatenga district, the main cultivations are sorghum, millet and cotton. Livestock also plays an important role in the economy of the area. The erratic and scarce rainfall heavily affects agro-pastoral production. Moreover, the decline of rainfall in the last 40 years, combined with the progress of desertification, led to an increased vulnerability of the agro-pastoral systems. Since 2000, repeated crises occurred in the Sahel. In 2011, the insufficient, erratic and late rainfall caused a harvest decrease

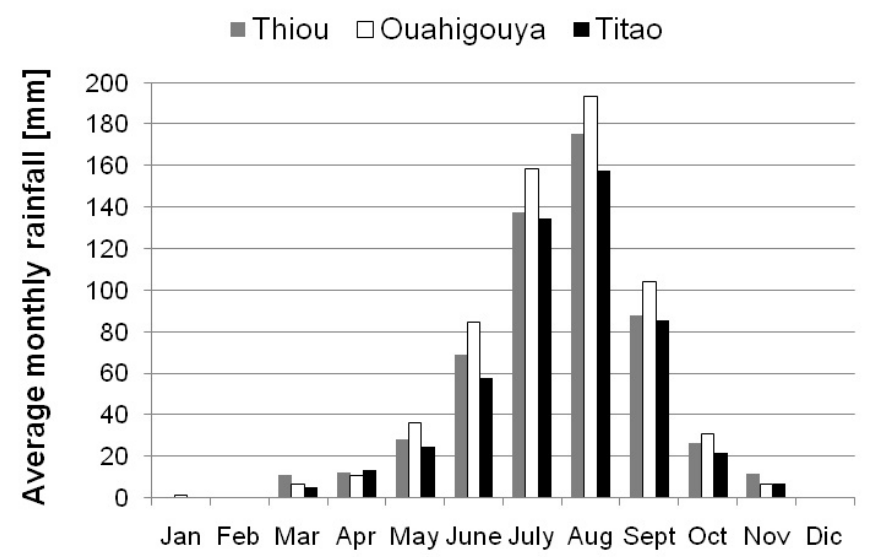

Figure 3.: Average monthly rainfall in millimeters in the period 1974-2011. 
and consequently 3 out of 5 rural villages have been officially declared at risk of food insufficiency (FAO 2012). FAO estimated a total need of more than 17 million USD to face the 2011 crisis just for Burkina Faso.

The soils suffer from water and wind erosion and degradation. In order to strengthen farmers and herders resilience to climatic variability it is necessary to increase the amount of stored water and improve irrigation structures and aqueducts. Traditional water harvesting systems have demonstrated to be effective in reducing water erosion and increase crop production in drought periods (Barry, Olaleye, and Fatondji 2008).

In such a context there are two clear outcomes:

1. Water storage is a critical factor for facing seasonal rain shortages and improving the chances of cultivation in the dry season.

2. The accurate and wide scale knowledge of the physical environment is crucial for planning and verifying appropriate actions for the improvement of the standard of living.

\section{Topographic analysis}

The topographic information is the prerequisite for any activity aiming at natural resource conservation and management. Particularly in the fields of soil conservation and water management, highly detailed topographic data (map scale larger than 1:25000 or raster resolution less than $10 \mathrm{~m}$ ) are needed.

In humanitarian projects the use of appropriate topographic information is often limited by the scarce availability of low cost products and by the prohibitive cost of ad hoc products. Topographic maps are often freely available, but the map scale is not adequate for many applications and the maps are not up-to-date. For example, the West Africa Topographic Maps Series N504 of the U.S. Army Map Service (University of Texas Libraries n.d.) has a map scale of 1:250000 and was produced in 1955. Some more detailed topographic maps are produced locally, but they cover very limited areas. In the case of Burkina Faso only $36 \%$ of the country is covered by a topographic map with a scale of 1:50000, while for the entire country only the 1:200000 map is available. Moreover, these products are relatively expensive.

The derivation of DEMs from remotely sensed data has partly filled the gap. DEMs are now freely available with a global coverage, e.g. SRTM (90 m resolution) and ASTER (30 m resolution) (Coltelli et al. 1996; Tachikawa et al. 2011). However, the resolutions of the above cited DEMs are still too coarse for many applications relevant for the success of humanitarian projects.

In this section we describe the interferometric chain implemented in this project for the derivation of a detailed (9 $\mathrm{m}$ of resolution) DEM from SAR images.

\subsection{Digital elevation model extraction}

SAR interferometry is a well-established and powerful instrument for topographic mapping (Rosen et al. 2000). In our work, we implemented an interferometric processing chain, whose rationale is outlined in 4 . In the following, we provide basic details on the blocks reported in 4 .

\subsubsection{Image coregistration}

The first step of the processing chain is the coregistration of the two interferometric images via a three steps procedure ( $\mathrm{Li}$ and Bethel 2008). In particular, a 


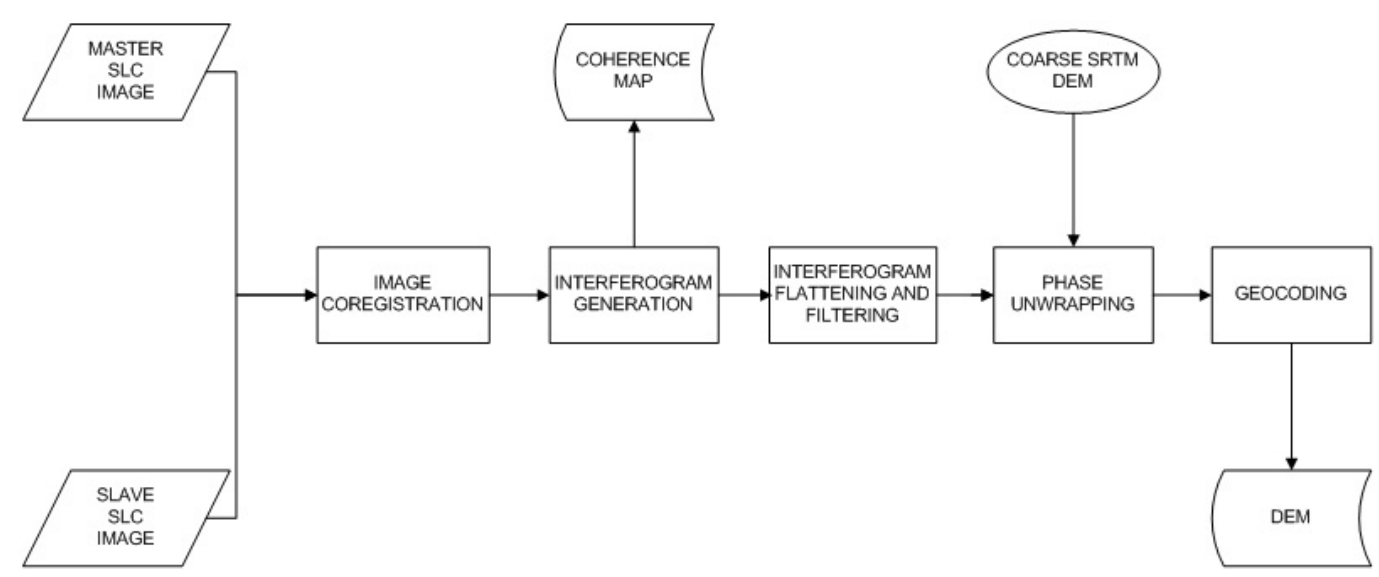

Figure 4.: Block scheme of the interferometric chain.

first image alignment is obtained using orbital information and solving the RangeDoppler equations (Franceschetti and Lanari 1999); then, a coarse coregistration is performed maximizing the intensity cross-correlation on $256 \times 512$ windows; finally, a fine subpixel shift is evaluated maximizing the over-sampled (by a factor 2) coherence within $32 \times 32$ sliding windows.

\subsubsection{Interferogram generation}

Once the two images are coregistered, the interferogram and the coherence map can be evaluated (Rosen et al. 2000). The obtained coherence map is shown in Figure 5 a. Due to the scarce presence of water and vegetation at the end of the dry season the obtained interferometric coherence is high over the entire area. More than $67 \%$ of the pixels have a coherence value higher than 0.5. The low-coherence pixels refer to areas located close to the biggest water reservoirs. This is a key prerequisite for obtaining high-quality DEMs. As known, the expected standard deviation of the height $\sigma_{z}$ and of the interferometric phase $\sigma_{\phi}$ are related by relation:

$$
\sigma_{z}=\frac{\lambda r \sin \theta}{4 \pi B_{\perp}} \sigma_{\phi}
$$

where $\sigma_{\phi}$ is a function of the coherence coefficient (see (Lee et al. 1998) for details). As instance, for the geometry of our pair, the wavelength is $\lambda=3.125 \mathrm{~cm}, r$ at center scene is about $767 \mathrm{~km}, B_{\perp}$ is $280.1 \mathrm{~m}$, the look angle $\theta$ is $37^{\circ}$. With these values, for a coherence value of 0.5 , that corresponds to a $\sigma_{\phi}$ of 0.5 radians with the applied number of looks, the expected $\sigma_{z}$ turns out to be about $2 \mathrm{~m}$.

A complex $3 \times 3$ multilook is applied at this step, in order to mitigate detrimental speckle effects corrupting the interferogram phase. This implies a decrease in spatial resolution from 3 (original COSMO-SkyMed single-look product resolution) to 9 meters (final DEM resolution).

\subsubsection{Interferogram flattening and filtering}

The obtained interferometric phase is a combination of the topographic, the flat Earth and the noise phases. The last two terms must be reduced before phase unwrapping. The interferogram flattening is performed with the aid of a radarcoded synthetic DEM, obtained from a standard SRTM DEM of the area (Monti Guarnieri et al. 2003). The residual speckle is mitigated through the application of the adaptive Lee phase filter with a negligible loss in resolution (Lee et al. 1998). In Figure $5 \mathrm{~b}$ the interferometric phase obtained after the filtering step is shown. 


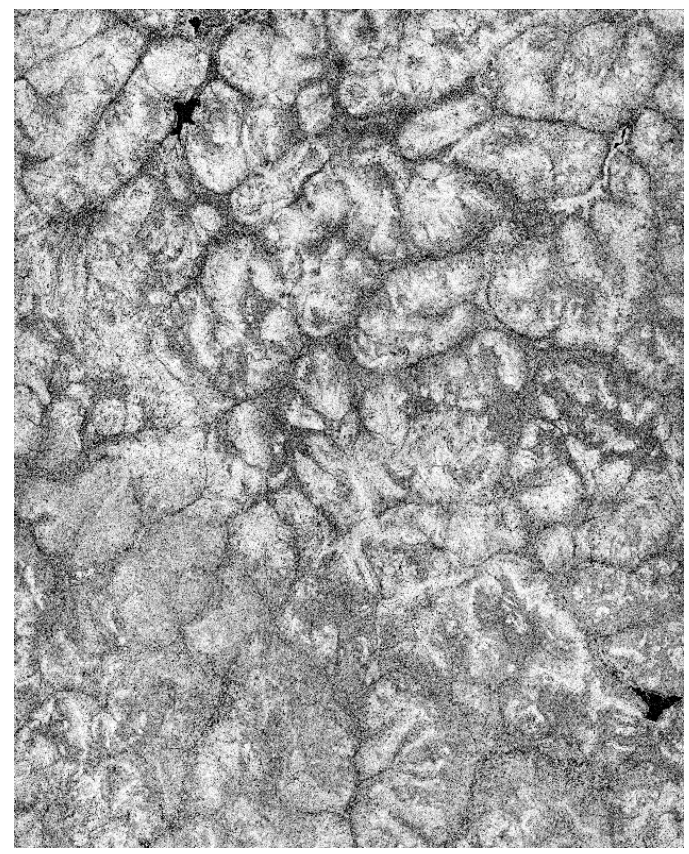

(a)

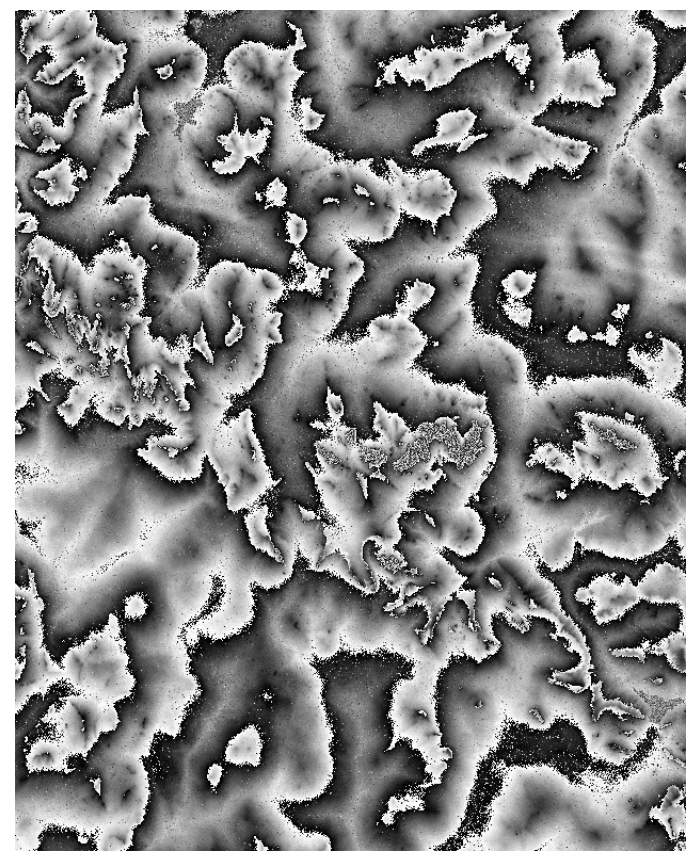

(b)

Figure 5.: Coherence map (a) and flattened filtered interferogram phase (b).

\subsubsection{Phase unwrapping and geocoding}

The obtained phase is than unwrapped with the SNAPHU algorithm, which is based on a statistical minimum-cost flow network method (Chen and Zebker 2001). After conversion from phase to height, the final DEM is geocoded and ready to be displayed in a geographic cartographic reference system.

The obtained DEM is shown in Figure 6. A particular relevant to the area of the Laaba basin is shown in Figure 7.

The obtained DEM has been compared with the available coarser resolution DEMs (SRTM and ASTER), as presented in Figure 8, and with GPS ground truth acquired during an on-site measurement campaign, as shown in Table 1.

The agreement of the obtained DEM with in-situ measurements is approximately in the order of the GPS accuracy, demonstrating the effectiveness of the proposed framework.

Table 1.: Comparison between the WARM-SAR DEM and 4 GPS points assumed as ground truth

\begin{tabular}{lcccc}
\hline Corner id & Position (GPS) & ASTER $(\mathrm{m})$ & SRTM $(\mathrm{m})$ & WARM DEM $(\mathrm{m})$ \\
\hline 1 & $13^{\circ} 55^{\prime} 03.6^{\prime \prime} N, 2^{\circ} 29^{\prime} 40.1^{\prime \prime} W, 309 \mathrm{~m}$ & $307(-2)$ & $312(3)$ & $312(3)$ \\
2 & $13^{\circ} 53^{\prime} 38.8^{\prime \prime} N, 2^{\circ} 29^{\prime} 49.6^{\prime \prime} W, 312 \mathrm{~m}$ & $306(-6)$ & $316(4)$ & $314(2)$ \\
3 & $13^{\circ} 50^{\prime} 04.9^{\prime \prime} N, 2^{\circ} 24^{\prime} 38.8^{\prime \prime} W, 358 \mathrm{~m}$ & $354(-4)$ & $359(1)$ & $356(-2)$ \\
4 & $13^{\circ} 41^{\prime} 45.8^{\prime \prime} N, 2^{\circ} 11^{\prime} 57.5^{\prime \prime} W, 333 \mathrm{~m}$ & $327(-6)$ & $335(2)$ & $335(-1)$ \\
\hline
\end{tabular}

The DEM reliability has also been tested in a different and original way. The border line of the water retention basins located in the study area can be observed in the SAR images at different time steps, both in wet and dry seasons. Due to the marked climate seasonality, the perimeters of the small reservoirs range from zero, in the dry season, to the value corresponding to the maximum water intake in the wet season. The reservoirs borders constitute topographic contour lines. Therefore, 


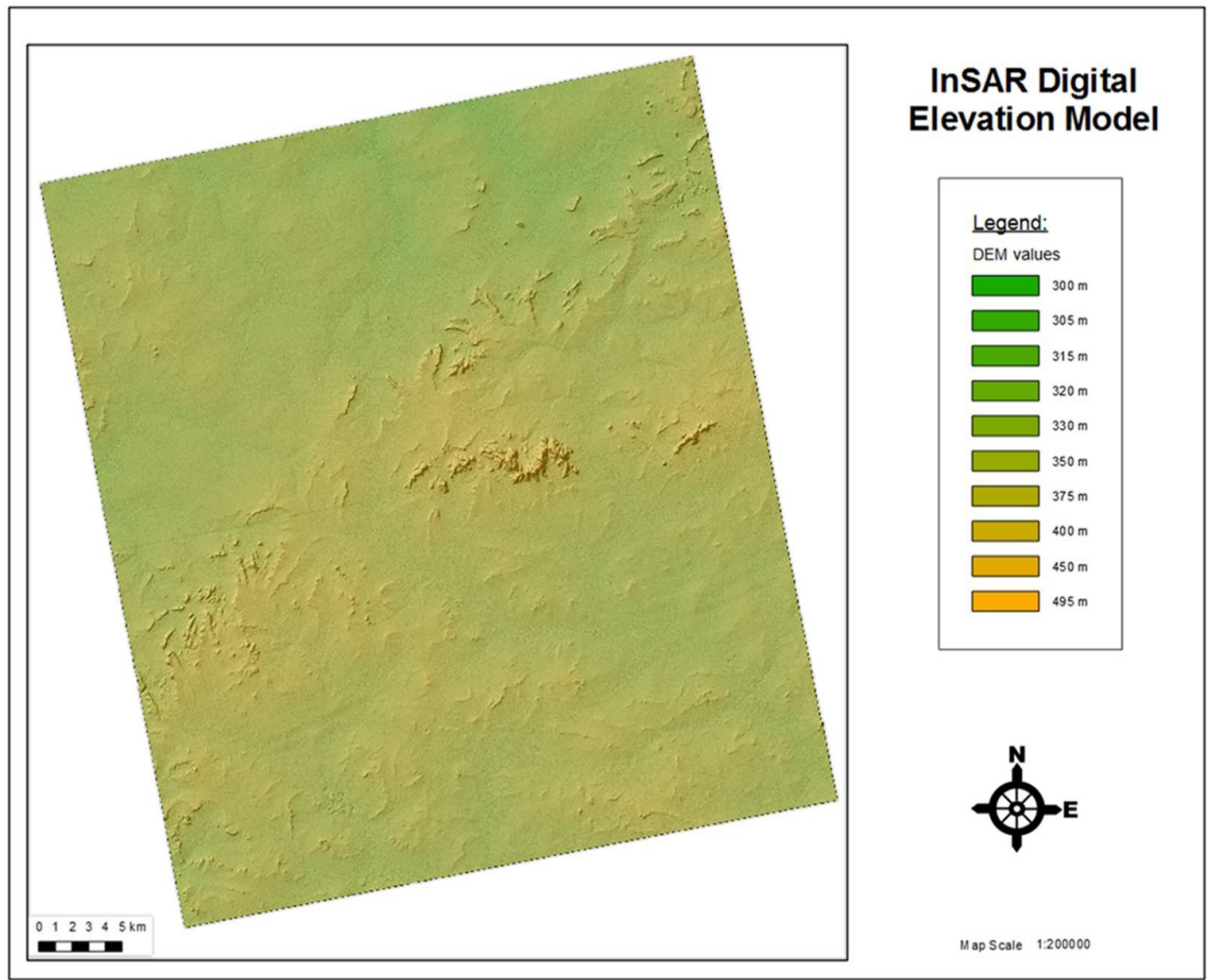

Figure 6.: Georeferenced DEM. It covers an area of $40 \times 40 \mathrm{~km}^{2}$. The spatial resolution is $9 \mathrm{~m}$.

the DEM reliability can be estimated through the comparison of water borders and contour lines computed on the basis of the DEM. In (Figure 9) and (Figure 10) two examples of such a comparison are shown, corresponding to the Laaba and Derhogo reservoirs, respectively. In the Laaba reservoir the DEM accurately reproduce a hole that was dug to free the inlet of the irrigation canal buried by the deposited sediments (see Figure 9).

It is worth noting that the method for DEM validation here presented may be exported to other similar contexts, provided that the climate conditions and reservoir size determine an almost complete drying up of the reservoirs in at least one moment of the year. For the north of Burkina Faso, the procedure may be employed for small size reservoirs (water depth lower than $2.5 \mathrm{~m}$ ). The method cannot be applied to reservoirs under a minimum size, dictated by the resolution of the DEM. In the analysis presented here, the smallest reservoir considered has a capacity of about $15000 \mathrm{~m}^{3}$.

\subsection{DEM-based monitoring of reservoirs sedimentation and soil erosion}

The DEM is the basis for the planning of development policies, for the protection (and management) of natural resources and for the design of engineering works. In this paper, an example application is presented in which the estimations of reservoir sedimentation and average water erosion rate are based on the analysis of the DEM. Soil erosion due to water and consequent sedimentation of reservoirs are 


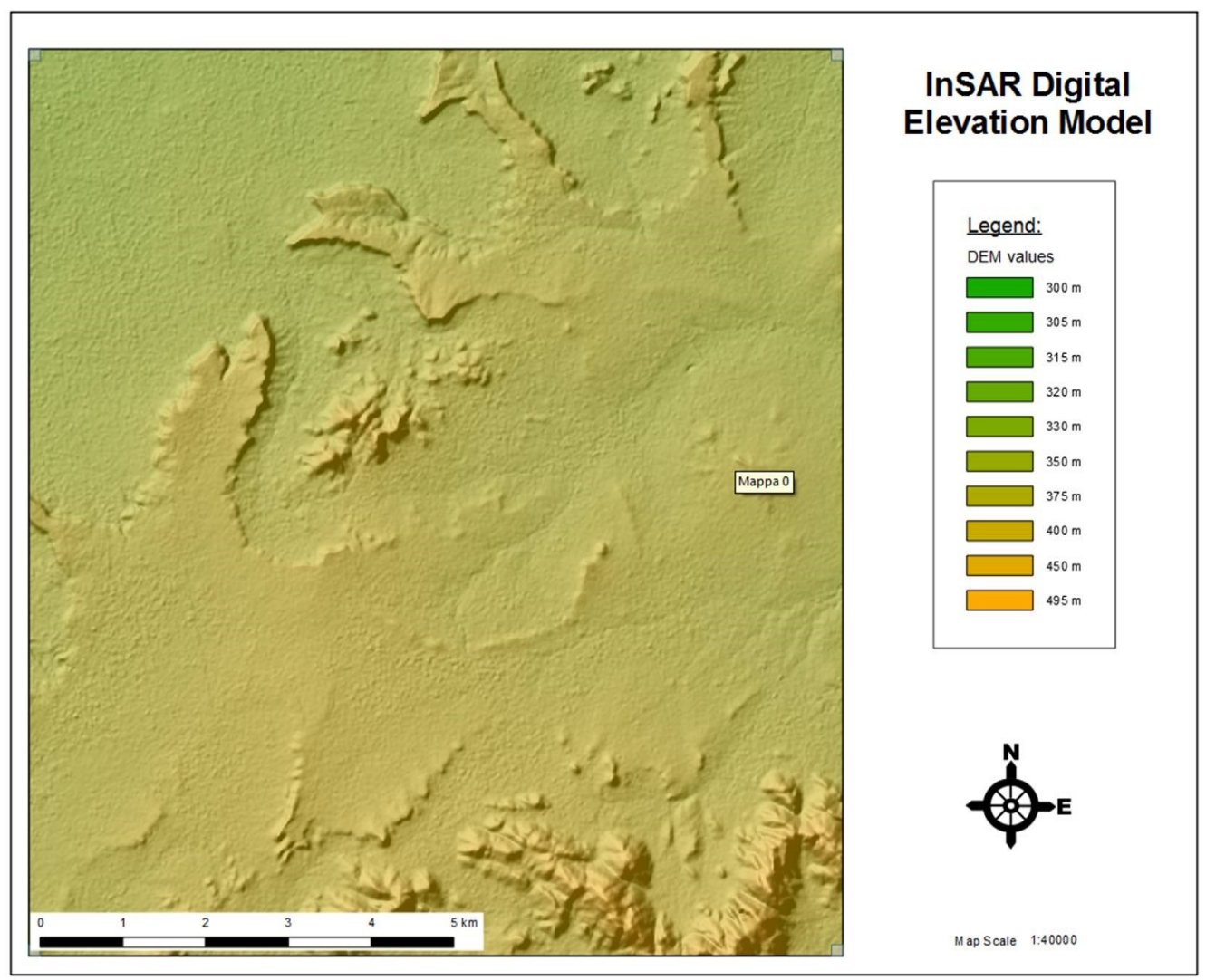

Figure 7.: Particular of the DEM relevant to the Laaba basin area.

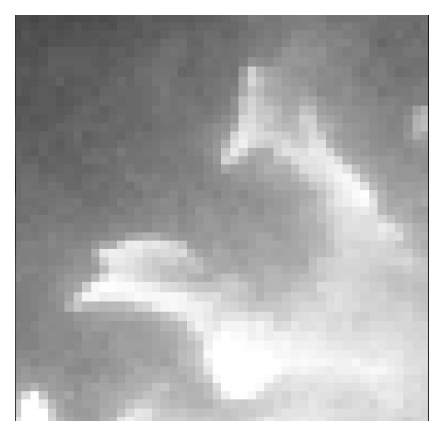

(a)

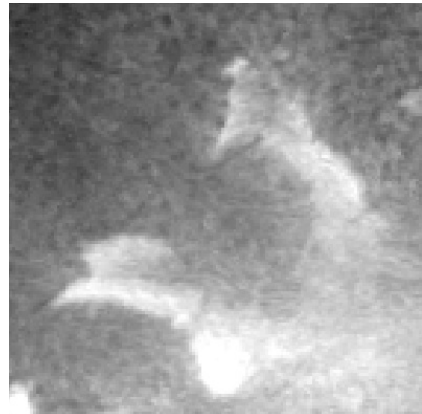

(b)

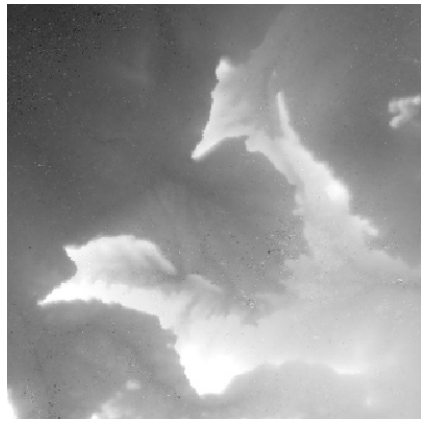

(c)

Figure 8.: DEM obtained in the framework of WARM project compared to previously available DEMs SRTM: resolution $90 \mathrm{~m}$ (a), ASTER: resolution $30 \mathrm{~m}$ (b), WARM: resolution $9 \mathrm{~m} \mathrm{(c).}$

major problems in West Africa (Pimentel et al. 1995; Lal 1993; Warren, Batterbury, and Osbahr 2001). Soil erosion determines a decline of soil productivity and it is one of the causes of the low levels of crop yields in the area. The life span of reservoirs and the amount of water available for agriculture are affected severely by reservoir sedimentation (Grimaldi et al. 2013).

Data on the original capacity $\left(V_{0}\right)$ and the year of construction $\left(t_{0}\right)$ of the reservoirs were derived from a database "base de donnes sur les ressources en eau" (DGH 1996) written in 1996 by the Direction Gnrale de IHydraulique (DGH) of Burkina Faso. In this database, we identified 8 reservoirs located in the study area (Table 2). 

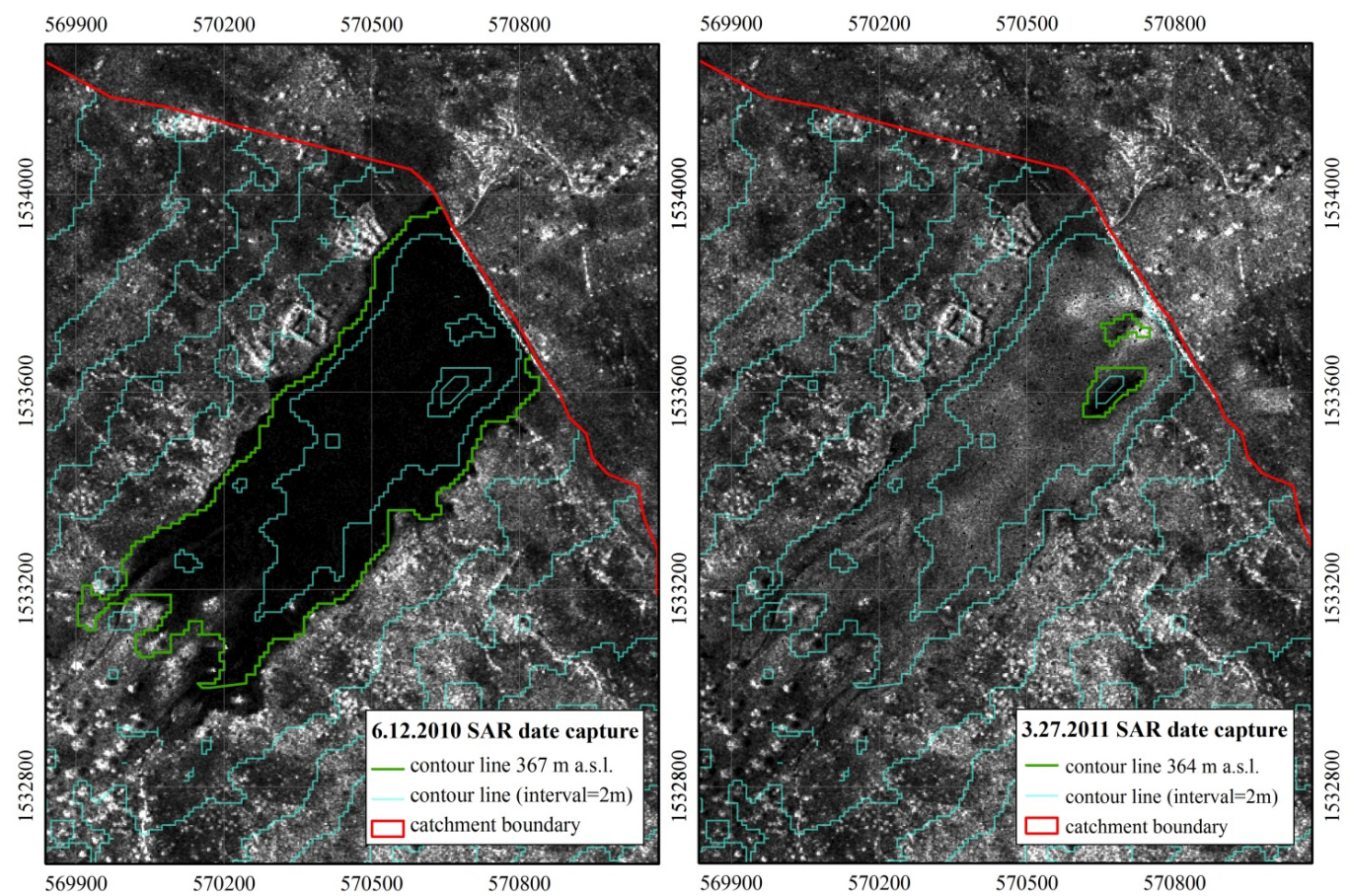

Figure 9.: Comparison between DEM derived contour lines and reservoirs border lines at Laaba.

Table 2.: Reservoir database

\begin{tabular}{|c|c|c|c|c|c|c|}
\hline Reservoir & $\begin{array}{c}\text { Year of } \\
\text { construction }\end{array}$ & $\begin{array}{l}\text { Original } \\
\text { capacity } \\
\left(10^{3} \mathrm{~m}^{3}\right)\end{array}$ & $\begin{array}{c}\text { Capacity } \\
\text { in } 2011 \\
\left(10^{3} \mathrm{~m}^{3}\right)\end{array}$ & $\begin{array}{l}\text { Sedimentation } \\
\left(\mathrm{m}^{3} / \text { year }\right)\end{array}$ & $\begin{array}{c}\text { Drained } \\
\text { catchment } \\
\left(\mathrm{km}^{2}\right)\end{array}$ & $\begin{array}{c}\text { Average } \\
\text { catchment } \\
\text { erosion }\left(10^{3} \mathrm{~kg} /\right. \\
(\text { ha } \times \text { year }))\end{array}$ \\
\hline Pogoro & 1987 & 330 & 0 & 13750 & 55.9 & 3.7 \\
\hline Saya & 1981 & 20 & 0.02 & 666 & 0.3 & 31.6 \\
\hline Gouinre & 1967 & - & - & - & 141.5 & - \\
\hline Gourga & 1988 & 24 & 0.06 & 1041 & 43 & 0.4 \\
\hline Ouahigouya & 1977 & 2700 & - & - & - & - \\
\hline Dinguela & 1985 & 22 & 5.9 & 732 & 5.5 & 2 \\
\hline Derhogo & 1987 & 14 & 3.8 & 425 & 4.2 & 1.5 \\
\hline Laaba & 1989 & 602 & 572 & 1364 & 15.5 & 1.3 \\
\hline
\end{tabular}

The residual reservoir capacity in the year $2011(V)$ was obtained from DEM. All DEM operations described here were performed in a geographic information system (GIS) environment. An open-source GIS dedicated to hydrological and geomorphological ana- lyses was used the Java Geographic Resources Analysis Support System (JGrass). A simple routine for evaluating V for any of the eight reservoirs was compiled by implementing the following formula:

$$
V=\sum_{i=1}^{n}\left(z_{w}-Z_{i}\right) \delta^{2}
$$

where $z_{w}$ is the maximum water level in the reservoir, $Z_{i}$ is the elevation of the pixel $i, \delta$ is DEM resolution, and $n$ is the total number of pixels of the reservoir. The two largest reservoirs could not be monitored using the technique developed because these also hold a large amount of water in the dry season. As it is not 


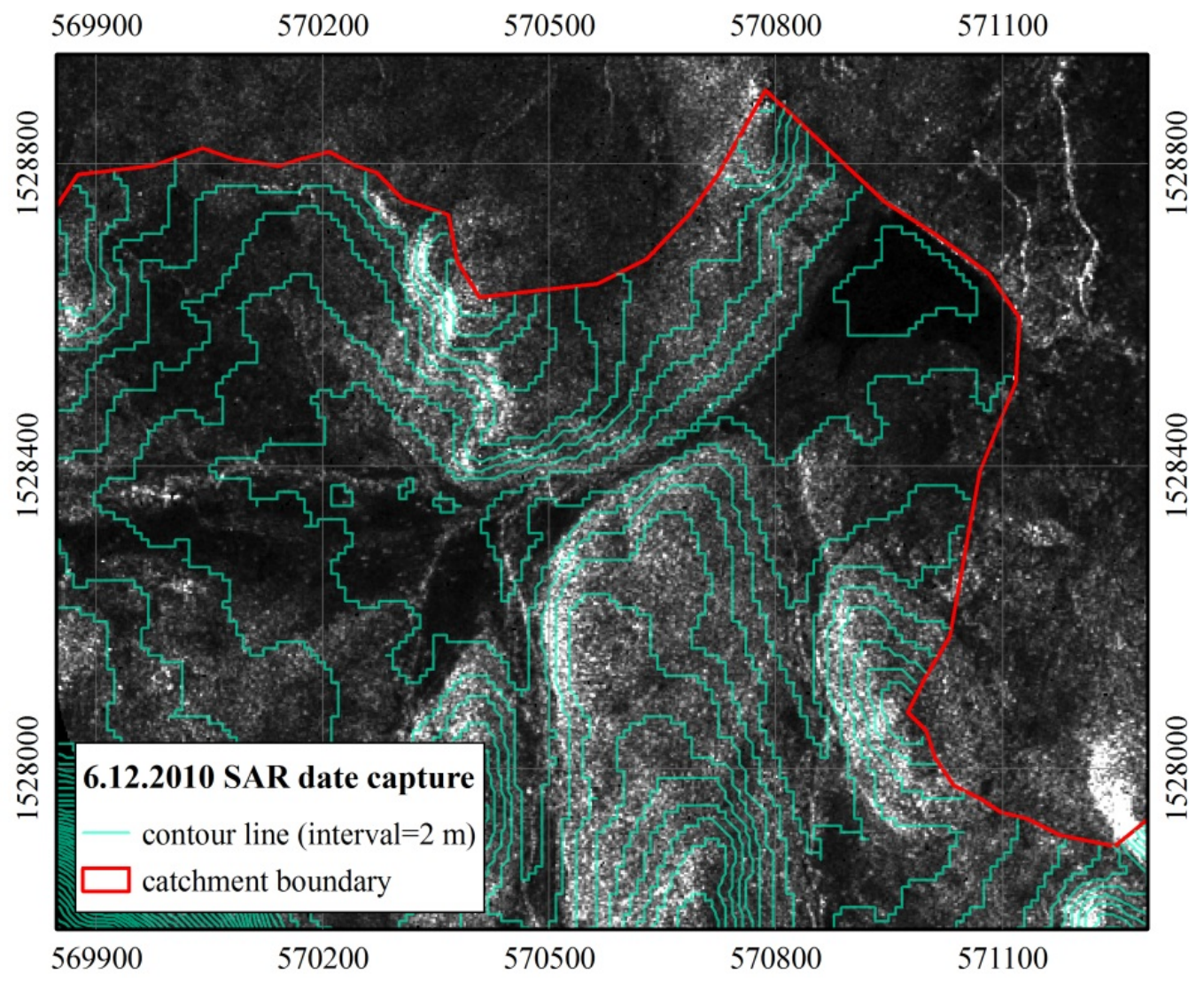

Figure 10.: Comparison between DEM derived contour lines and reservoirs border lines at Derhogo.

possible to derive DEM for areas covered by water, we could not estimate the reservoir capacity for these basins.

The average annual loss in reservoir capacity $(S)$, due to sedimentation of solid material transported by the tributary river, was estimated using the following equation:

$$
S=\frac{V-V_{0}}{t-t_{0}}
$$

where $V$ is the residual reservoir capacity evaluated in the year $t, V_{0}$ is the original capacity, and $t_{0}$ is the year of dam construction. The resulting $S$ is expressed in $\mathrm{m}^{3} /$ year.

Because of the high rate of soil erosion in the area (Warren, Batterbury, and Osbahr 2001) in about 25 years most of the reservoirs lost from 50 to $100 \%$ of their original capacity.

When the catchments drained by the dams are entirely included in the SAR images, it is possible to extract the catchments area by elaborating the DEM. The boundaries of the drained catchments have been derived with JGrass tools. Neglecting the sediment volume that may overflow the dam, and the possible loss of sediment due to reservoir dredging, it is possible to provide a rough estimation of the average soil erosion $E$ : 


$$
E=\frac{S}{A}
$$

where $A$ is the area of the catchment drained by the dam.

The values reported in Table 2 are obtained assuming a sediment apparent density of $1500 \mathrm{~kg} / \mathrm{m}^{3}$ (Lamachere 1998). The obtained values are in the range of the values estimated for the area (Lamachere 1998; Warren, Batterbury, and Osbahr 2001). The catchment drained by the Saya dam shows an average soil loss that is one order of magnitude greater than the others. This peculiarity determined a change of use of the reservoir that is no longer used for collecting water, but is exploited for the extraction of silt for bricks production.

The technique here presented may be employed for monitoring reservoir sedimentation, and consequently the soil erosion at catchment scale, on an annual basis. To do this, a couple of interferometric SAR images should be regularly acquired each year at the end of the dry season, i.e. in April, in order to obtain the DEM.

\section{Monitoring of water intake in small reservoirs}

In the Sahel, as well as in other parts of the world where the climate conditions lead to severe seasonal water shortages, the water reservoirs are essential for livestock watering, irrigation, groundwater recharge, human consumption and other purposes. In Burkina Faso there are 1450 registered reservoirs (Cecchi et al. 2009). Half of the registered reservoirs were built between 1974 and 1987, during a dramatic drought that affected all West Africa. Almost 900 of Burkina Faso reservoirs are small-sized, with a capacity of less than $1 \mathrm{Mm} 3$. They constitute an essential water resource for the local livelihood. In many places, the creation of small reservoirs has resulted in increased household income through productive agricultural activities upstream and downstream of the reservoir (Liebe, van de Giesen, and Andreini 2005). Despite that, there is a pernicious lack of information about the number, size, location and functioning of these reservoirs. These often prevent efficient water management and reservoir maintenance.

Moreover, the information on water volumes collected by the dams may be used as a surrogate of runoff gauges measurements (Liebe et al. 2009b). Given the chronic lack of hydrological data, especially in developing countries, this information may be crucial for developing hydrological models.

As a matter of fact, the analysis of the hydrology of an area needs sufficient historical information. This theme is so essential that the International Association for Hydrological Sciences (IAHS) has promoted the initiative "Prediction in Ungauged Basins"(PUB), a scientific mission aimed at reducing uncertainty in hydrological forecasting and promoting new reference models for the management of land and water (Sivapalan 2003).

The monitoring of the small reservoirs may be derived by optical imagery (Frazier and Page 2000; Liebe, van de Giesen, and Andreini 2005), only in absence of cloud-cover and therefore it is not possible to observe the reservoirs in the rainy season, when they are completely full. Another drawback of optical images is that they may provide only the water surface area and expensive bathymetric surveys are needed to derive the correspondent water volumes.

In the approach here presented the bathymetry of the reservoirs is derived from the DEM, as explained in the previous paragraph, and the water surface areas are 
estimated at different time steps from SAR images. The extraction of water surface from SAR data is possible because the water acts as a mirror, reflecting most of the incident field in specular direction. Therefore, the SAR sensor measures a weak backscattered signal that corresponds to a dark area in the SAR image. The extraction procedure performances are limited by the presence of speckle (Ulaby, Moore, and Fung 1986). In this paper, we employ a multi-time de Grandi filtering for reducing the speckle and preserving the original spatial resolution (de Grandi et al. 1997). An example of the effects of the filtering process is shown in Figure 11, where we compare the SAR image of the Laaba dam before and after the filtering procedure.

In Figure 11b we can observe that the significant reduction of the speckle did not deteriorate the spatial borders, allowing a more reliable extraction of water surface boundaries. In addition, the contrast between the open water and the surrounding environment is increased. In Figure 12 the comparison between the pre- and postfiltering histograms of the SAR image show that the employed procedure allows a separation between the open water and the surrounding soil, that leads to a reliable automatic segmentation procedure.

The water surfaces extracted from SAR images have been overlapped to the DEM in a GIS environment and the corresponding water volumes $\left(W_{t}\right)$ at time $t$, have been computed implementing the following equation:

$$
W_{t}=\sum_{i=1}^{m_{t}}\left(Z_{t}-Z_{i}\right) \delta^{2}
$$

where $m_{t}$ is the number of pixels that are covered by water at time $t$ and $Z_{t}$ is the elevation of the water surface at time $t . Z_{t}$ is set to the elevation of the contour line that fits the boundary of the water surface at time $t . Z_{i}$ is the elevation of the pixel, that is derived from the DEM. The depth of sediment deposited in one year is assumed negligible and therefore $Z_{i}$ is supposed stationary in the year. In Figure 13 an example is reported of the application of the proposed technique to the Laaba reservoir. For comparison, temperature and daily rainfall measured at Ouahigouya station are reported. The Ouahigouya station is at $329 \mathrm{~m}$ a.s.l. and is about 35 $\mathrm{km}$ far from Laaba reservoir (365 $\mathrm{m}$ a.s.l.). As it can be seen in the graph, a few rainy days at the beginning of the rainy season are enough to fill up the small reservoir. During the rainy season emergent vegetation may grow up in the tail part of the reservoir and this is probably the reason why we observe an apparent decrease in the water surface. In fact, in SAR images the presence of emerging vegetation at the boundaries of the water basins can determine the occurrence of volume and multiple scattering phenomena, which can limit the possibility of an accurate extraction of the reservoir extent. This phenomenon is known in literature (Annor et al. 2009; Horrit et al. 2003; Liebe et al. 2009a; Wang et al. 1995) and different techniques have been developed in order to correct it (Mason et al. 2012). However, these techniques are based on some kind of a priori knowledge about the vegetation (type of vegetation, average height and so on), which is currently not available with sufficient detail in the area of interest (Annor et al. 2009; Liebe et al. 2009a). Further studies will be necessary in order to correct these kinds of effects and improve reservoir water extent evaluation during the rainy season. These errors are not relevant to the estimation of the water surface areas at the beginning of the rainy season, as the vegetation is almost absent in that period of the year.

In conclusion, the water surface area may be estimated for reservoirs of any size, 


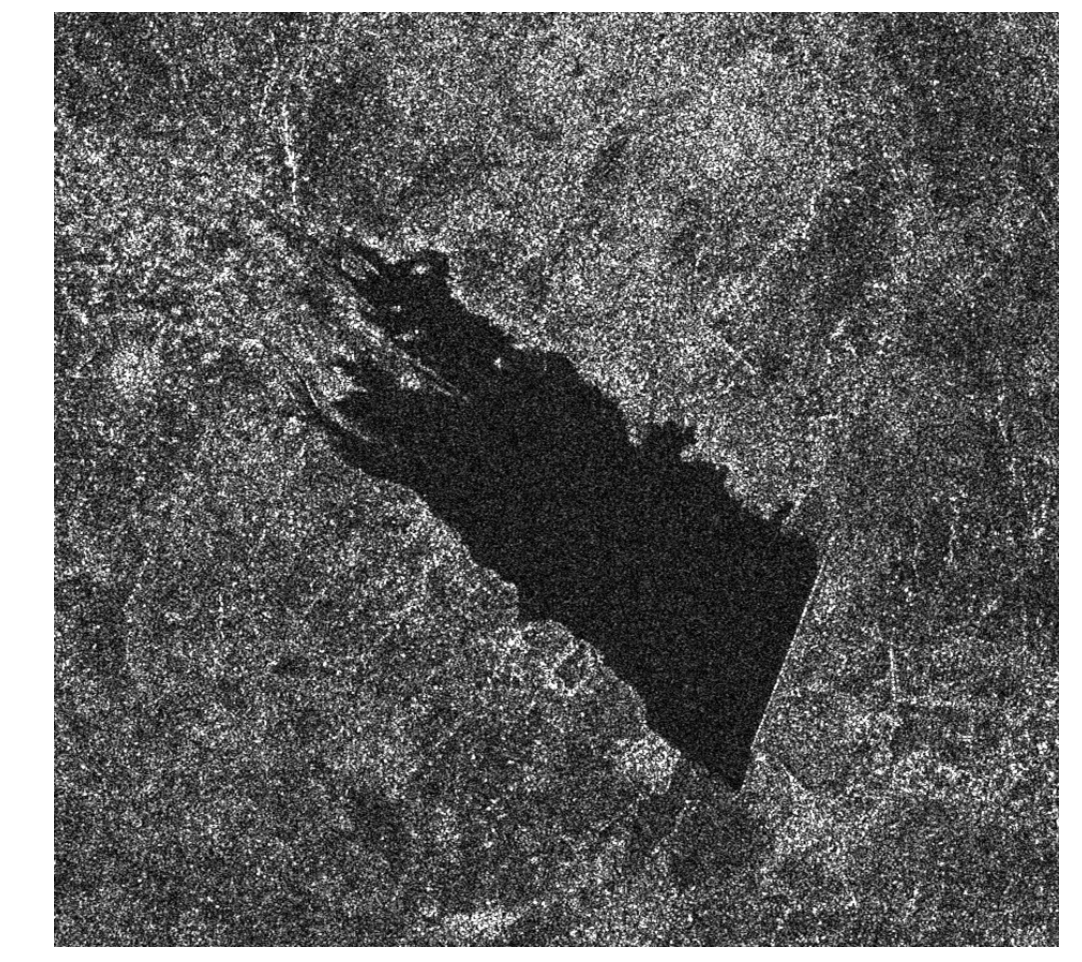

(a)

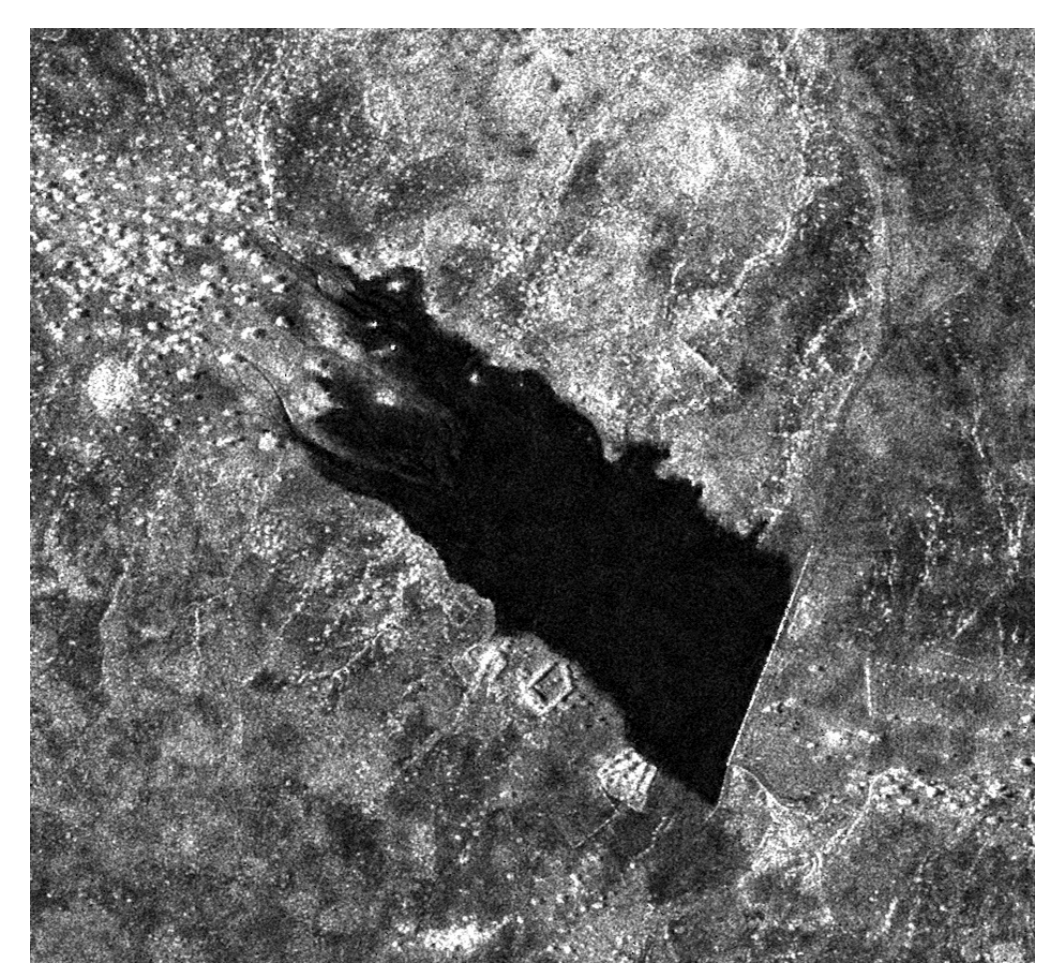

(b)

Figure 11.: Stripmap Single look (a) and de Grandi filtered (b) SAR image of the Laaba dam, acquired on 12 June 2010.

but the possibility of extracting the bathymetry, and therefore the water volumes, is only possible for basins that completely dry at least once a year.

(a)

. 


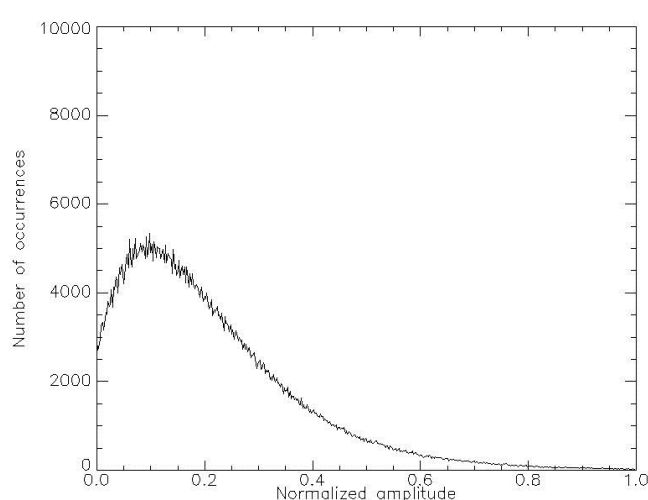

(a)

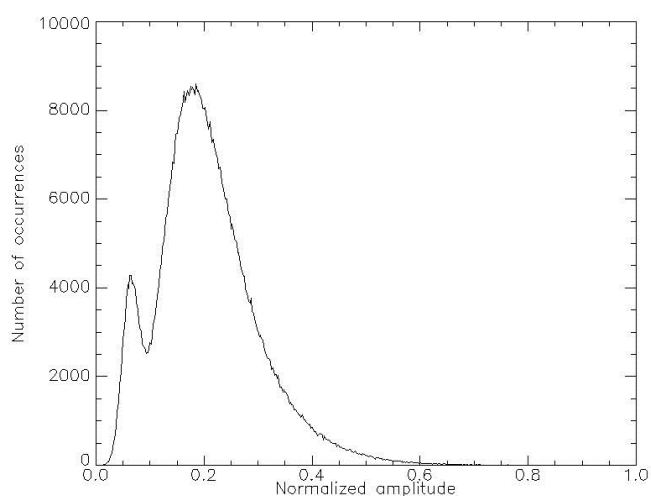

(b)

Figure 12.: Histogram relative to the single look (a) and filtered (b) SAR image of the Laaba dam, acquired on 12 June 2010.
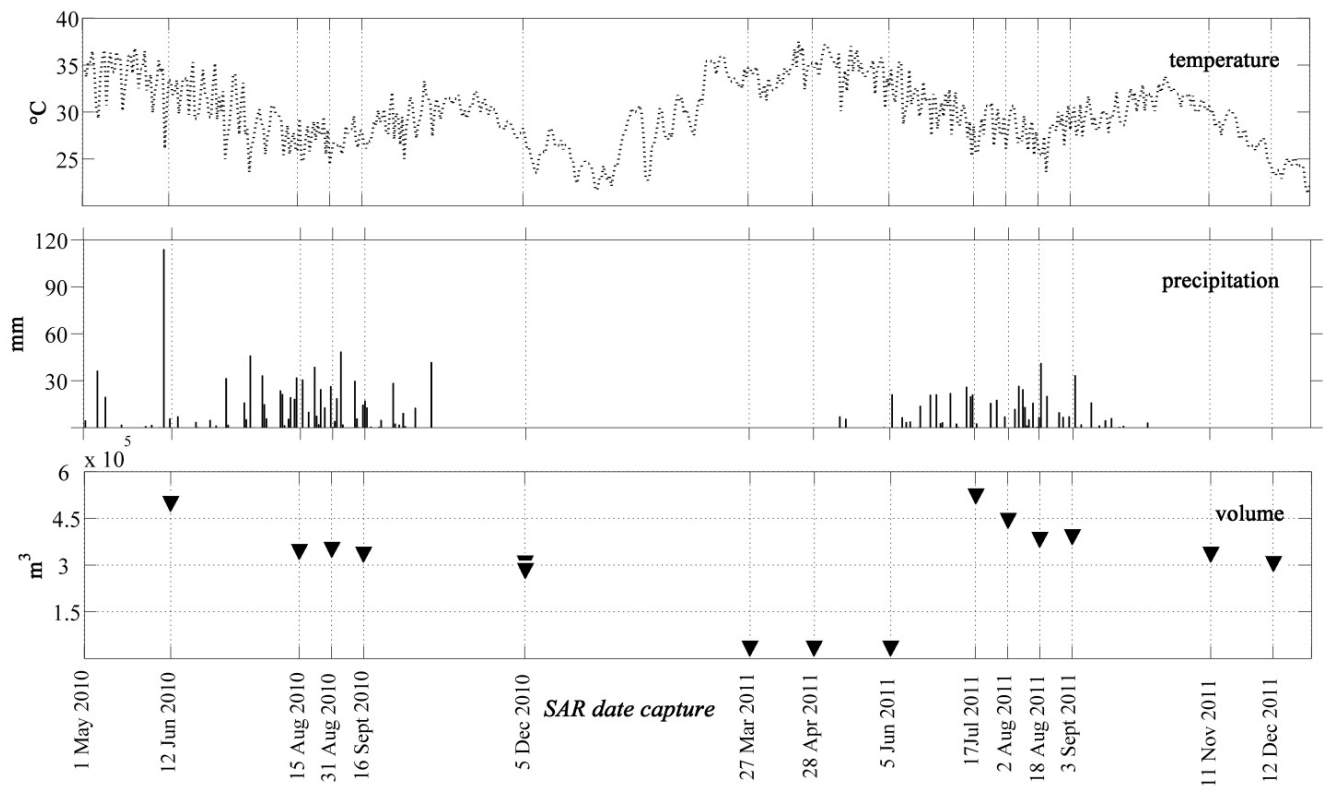

Figure 13.: Time series of temperature (in Celsius degrees) and daily rainfall (in millimeters) at Ouahigouya meteo station and water volume (in $\mathrm{m}^{3}$ ) at Laaba reservoir.

\section{Conclusions}

In this paper an innovative approach is presented for the effective use of high resolution SAR data for water-related applications in low-income semi-arid regions. In particular, we retrieved from COSMO-SkyMed SAR images appropriate information to support decisions on water resource management. The approach was implemented in a pilot project in the North of Burkina Faso (Yatenga district), a low-income country in the West-African Sahel. The project was based on the integration of complementary skills in the fields of remote sensing and hydrology and adapted to the needs of local stakeholders and to the social, economic and physical details of the study area.

The SAR images were acquired in both the two extreme climatic conditions (rainy 
and dry) that characterize the area. A digital elevation model of the study area was obtained via standard interferometry processing of the images taken in the dry season. Thanks to the stable climatic conditions and the almost complete absence of vegetation cover in the scene of interest, the dry season images have high interferometric coherence $(67 \%$ of the investigated area has a coherence map higher than 0.5). Dedicated GPS acquisitions demonstrated that the DEM accuracy is comparable to the GPS precision. An innovative method of verification of the DEM quality has been also presented with the combined use of phase and amplitude data. In fact, the contour lines obtained by the DEM have been compared with the boundaries of the reservoirs in order to estimate the DEM precision. The great advantage of the proposed method is that it gives the possibility of verifying a SAR product by the means of another SAR product, without the need of expensive field campaigns. Thanks to the COSMO-SkyMed high resolution, we obtained an increase of resolution of one order of magnitude with respect to the previously available SRTM DEM.

According to the authors knowledge, this is the highest resolution DEM available for the area of interest. Such a result is important mainly in low income countries, where the absence of reliable and high resolution topographic data is a major problem in engineering applications. The obtained DEM is not only important per se but mainly for the several applications that it can support. In areas experiencing a sufficiently long dry and hot season, such as the study area considered here, the small sized artificial water intakes dry up completely every year. Since the evaporation rates are larger than 2.0 meters per year, the water intake of the study area having water depth lower than 2.5 meters are completely empty in the dry season. For these basins the DEM produced from SAR images acquired in the dry season provides the shape of the reservoirs. Therefore, the actual maximum capacity of the reservoir may be estimated. The reservoir capacity decreases rapidly in the studied area because of reservoir sedimentation. For the aim of effectively managing the water resources and forecasting water related crisis, it is crucial to survey the actual reservoir capacity in sensitive areas.

The estimation of the sedimentation rate of reservoirs has been also performed. This element, combined with the DEM-based identification of the drained catchments, allowed the estimation of the average soil erosion at basin scale. The developed tool constitutes an innovative and low-cost SAR-based technique for the estimation of soil erosion in semi-arid areas.

The integration of the obtained DEM with the SAR amplitude images, allowed the development of innovative algorithms for the monitoring of water intake in reservoirs and its evolution in time. With the developed technique, a synoptic view of the total water volume available in the reservoirs of an entire region can be provided. This information, often missing in low income countries, is crucial for an appropriate management of water-use and for the prevention and mitigation of water crisis.

The obtained results show that remote sensing in general and SAR images in particular, hold enormous potentialities, mainly in the poorest areas of the Earth and that their use can provide significant advantages to all the involved stakeholders.

\section{Acknowledgements}

The authors thank the Direction de la Meteorologie du Burkina Faso for providing the rainfall and temperature measurements of Ouahigouya meteo station and the Salerno and Napoli sections of Engineering Without Borders for supporting the 
missions of researcher and volunteers in Burkina Faso.

The SAR images, at the basis of the study, were provided by the Italian Space Agency (ASI) in the frame of the 2007 COSMO-SkyMed AO Project "Use of High Resolution SAR Data for Water Resource Management in Semi Arid Regions".

\section{References}

Albergel, J., and J.-M. Lamachre. 1993. "Un climat tranch." In Mise en valeur agricole des bas-fonds au Sahel: typologie, fonctionnement hydrologique, potentialits agricoles: rapport final d'un projet, edited by J. Albergel and J.-M. Lamachre. 43-52. CORAF-R3S.

Annor, F. O., N. van de Giesen, J. Liebe, P. van de Zaag, A. Tilmant, and S. N. Odai. 2009. "Delineation of Small Reservoirs Using Radar Imagery in a Semi-Arid Environment: A Case Study in the Upper East Region of Ghana." Physics and Chemistry of the Earth, Parts A/B/C 34 (4-5): 309-315.

Barry, B., A. O. Olaleye, and D. Fatondji. 2008. Rainwater harvestiong technologies in the Sahelian zone of West Africa and the potential of outscaling. Tech. rep.. Colombo, Sri Lanka: International Water Management Institute.

Bates, B. C., W. Kundzewicz, S. Wu, and J. P. Palutikof. 2008. "Climate change and water." In IPCC Technical Paper VI, Technical Paper of the Intergovernmental Panel on Climate Change, IPCC Secretariat, Geneva.

Castaing, C., M. Billa, J.P. Milsi, D. Thieblemont, J. Le Metour, F. Egal, and M. Donzeau. 2013. Carte Gologique Et Minire Du Burkina Faso 1:1,000,000 . Tech. rep.. Bureau de recherches gologiques et minires.

Cecchi, P., A. Meunier-Nikema, N. Moiroux, and B. Sanou. 2009. "Towards an Atlas of Lakes and Reservoirs in Burkina Faso." In Small Reservoir Toolkit, 1-23.

Chen, C. W., and H. A. Zebker. 2001. "Two-dimensional Phase Unwrapping with Use of Statistical Models for Cost Functions in Nonlinear Optimization." Journal of the Optical Society of America A 18 (2): 338-351.

Coltelli, M., G. Fornaro, G. Franceschetti, R. Lanari, M. Migliaccio, J. R. Moreira, K. P. Papathanassiou, G. Puglisi, D. Riccio, and M. Schwabisch. 1996. "SIR-C/X-SAR multifrequency multipass interferometry: A new tool for geological interpretation." Journal of Geophisical Research 101: 127-148.

de Grandi, G. F., M. Leysen, J. S. Lee, and D. Schuler. 1997. "Radar Reflectivity Estimation Using Multiple SAR Scenes of the Same Target: Technique and Applications." In IEEE International Geoscience and Remote Sensing Symposium, Vol. 201047-1050.

DGH. 1996. Inventaire des retenues deau au Burkina Faso. Tech. rep.. Burkina Faso: Coopration Nerlandaise: Direction Gnrale de l'Hydraulique.

Di Martino, G., A. Iodice, A. Natale, D. Riccio, G. Ruello, I. Zinno, Y. Koussoube, M. N. Papa, and F. Ciervo. 2012a. "COSMO-SkyMed AO Projects - Use of High Resolution SAR data for Water Resource Management in Semi Arid Regions." In IEEE International Geoscience and Remote Sensing Symposium, 1212-1215.

Di Martino, G., A. Iodice, D. Riccio, G. Ruello, M. N. Papa, and Y. Koussoube. 2012b. "Innovative Synthetic Aperture Radar Products for the Management of Land and Water." In IEEE International Geoscience and Remote Sensing Symposium, 1212-1215.

Di Martino, G., A. Iodice, D. Riccio, G. Ruello, I. Zinno, F. Ciervo, M. N. Papa, and Y. Koussoube. 2011. "Use of High Resolution Satellite Images for the Calibration of Hydro-geological Models in Semi-Arid Regions: A Case Study." In IEEE Global Humanitarian Technology Conference, 171-175.

ESA. 2012. 2009-2012 Report. The TIGER Initiative. Looking for Water in Africa. Tech. rep.. http://www.tiger.esa.int/files//pdf/tiger_report_single_pages_ lowres.pdf: European Space Agency.

FAO. 2012. The food and nutrition crisis in the Sahel. Urgent action to support the resilience of vulnerable populations - Regional Strategic Response Framework - Burkina Faso, Cameroon, Chad, the Gambia, Mali, Mauritania, the Niger and Senegal. Tech. 
rep.. Food and Agriculture Organization.

Fernandez, D., F. Palazzo, A. Lipponen, and S. Iris. 2009. "TIGER: Earth observation to improve African water resource management." In IEEE International Geoscience and Remote Sensing Symposium, 248-251.

Franceschetti, G., and R. Lanari. 1999. Synthetic Aperture Radar Processing. Boca Raton, FL: CRC Press.

Frazier, P. S., and K. J. Page. 2000. "Water Body Detection and Delineation with Landsat TM Data." Photogrammetric Engineering 8 Remote Sensing 66 (12): 1461-1467.

Grimaldi, S., V. Angeluccetti, V. Coviello, and P. Vezza. 2013. "Cost-effectiveness of soil and water conservation measures on the catchment sediment budget The Laaba watershed case study, Burkina Faso." Land Degradation and Development .

Horrit, M. S., D. C. Mason, D. M. Cobby, I. J. Davenport, and P. D. Bates. 2003. "Waterline Mapping in Flooded Vegetation from Airborne SAR Imagery." Remote Sensing of Environment 85 (3): 271-281.

INSD. 2006. Recensement gnral de la population du Burkina Faso 2005. Tech. rep.. Institut national de la statistique et de la dmographie du Burkina Faso.

Koussoube, Y. 2010. "Hydrogologie des sries sdimentaires de la dpression pizometrique du Gondo (bassin versant du Sourou) - Burkina Faso/Mali." Ph.D. thesis. Universit Pierre et Marie Curie Paris.

Lal, R. 1993. "Soil erosion and conservation in West Africa." In World Soil Erosion and Conservation, edited by D. Pimentel. 7-25. Cambridge: Cambridge University Press.

Lamachere, J.-M. 1998. Transports Solides a L'exutoire D'un Bassin Versant Sahelien (rgion De Bidi, Burkina Faso). Tech. rep.

Lee, J. S., K. P. Papathanassiou, T. L. Ainsworth, M. R. Grunes, and A. Reigber. 1998. "A New Technique for Noise Filtering of SAR Interferometric Phase Images." IEEE Transactions on Geoscience and Remote Sensing 36 (5): 1456-1465.

Li, Z., and J. Bethel. 2008. "Image Coregistration in SAR Interferometry." In The International Archives of the Photogrammetry, Remote Sensing and Spatial Information Sciences, XXXVII (B1), 433-438.

Liebe, J., N. van de Giesen, and M. Andreini. 2005. "Estimation of Small Reservoir Storage Capacities in a Semi-Arid Environment: A case study in the Upper East Region of Ghana." Physics and Chemistry of the Earth, Parts A/B/C 30 (6-7): 448-454.

Liebe, J., N. van de Giesen, M. Andreini, T. S. Steenhuis, and M. T. Walter. 2009a. "Suitability and Limitations of ENVISAT ASAR for Monitoring Small Reservoirs in a Semiarid Area." IEEE Transactions on Geoscience and Remote Sensing 47 (5): 15361547.

Liebe, J., N. van de Giesen, M. Andreini, M. T. Walter, and T. S. Steenhuis. 2009b. "Determining Watershed Response in Data Poor Environments with Remotely Sensed Small Reservoirs as Runoff Gauges." Water Resources Research 45 (7): 1-12.

Mason, D. C., G. J.-P. Schumann, J. C. Neal, J. Garcia-Pintado, and P. D. Bates. 2012. "Automatic near real-time selection of flood water levels from high resolution Synthetic Aperture Radar images for assimilation into hydraulic models: A case study." Remote Sensing of Environment 124: 705-716.

Monti Guarnieri, A., P. Guccione, P. Pasquali, and Y. L. Desnos. 2003. "Multi-mode ENVISAT ASAR Interferomety: Techniques and Preliminary Results." IEEE Proceedings Radar, Sonar and Navigation 150 (3): 193-200.

Peel, M. C., B. L. Finlayson, and T. A. McMahon. 2007. "Updated World Map of the Köppen-Geiger Climate Classification." Hydrology and Earth System Sciences 11: 16331644.

Perry, C., P. Steduto, R. G. Allen, and C. M. Burt. 2009. "Increasing Productivity in Irrigated Agricolture: Agronomic Constraints and Hydrological Realities." Agricultural Water Management 96 (11): 1517-1524.

Pimentel, D., C. Hervey, P. Resosudarmo, K. Sinclair, D. Kurz, M. McNair, and S. Crist et al. 1995. "Environmental and Economic Costs of Soil Erosion and Conservation Benefits." Science 276 (5315): 1117-1123.

Rosen, P. A., S. Hensley, I. R. Joughin, F. K. Li, S. N. Madsen, E. Rodrguez, and R. M. 
Goldstein. 2000. "Synthetic Aperture Radar Interferometry." Proceedings of the IEEE 88 (3): 333-382.

Sienou, A., and A. P. Karduck. 2012. "Logistics Challenges in Developing Countries: An Analysis of Burkina Faso." In IEEE International Conference on Digital Ecosystems and Technologies, 1-4.

Sivapalan, M. 2003. "Prediction in Ungauged Basins: a Grand Challenge for Theoretical Hydrology." Hydrological Processes 17 (15): 3163-3170.

Tachikawa, T., M. Hato, M. Kaku, and A. Iwasaki. 2011. "Characteristics of ASTER GDEM Version 2." In IEEE International Geoscience and Remote Sensing Symposium, 3657-3660.

Ulaby, F. T., R. K. Moore, and A. K. Fung. 1986. Microwave Remote Sensing, Active and Passive. Nordwood, MA: Artech House.

UNDP. 2011. Human Development Report 2011. Sustainability and Equity: A Better Future for All. Tech. rep.. http://hdr. undp.org/en/media/HDR_2011_EN_Complete.pdf: United Nations Development Programme.

University of Texas Libraries. n.d.. "Perry-Castañeda Library Map Collection." \url\{http://www.lib.utexas.edu/maps/burkina_faso.html\}.

van de Giesen, N. C., H. Kunstmann, G. Jung, M. Andreini, and P. L. G. Vlek. 2003. "The GLOWA Volta project: Integrated assessment of feedback mechanism between climate, land use, and hydrology." In Climatic Change. Implications for the Hydrological Cycle and for Water Management, Vol. 10 of Advances in Global Change Research edited by M. Beniston. Springer.

Wang, Y., L. L. Hess, S. Filoso, and J. M. Melack. 1995. "Understanding the Radar Backscattering from the Flooded and Non-flooded Amazonian Forests: Results from Canopy Backscatter Modeling." Remote Sensing of Environment 54: 324-332.

Warren, A., S. Batterbury, and H. Osbahr. 2001. "Soil Erosion in the West African Sahel: a Review and an Application of a Local Political Ecology Approach in South West Niger." Global Environmental Change 11 (1): 79-95. 